\section{The influence of programmatic diversity on the formation of new political parties}

Party Politics

20I5, Vol. 2I(6) 919-929

(c) The Author(s) 2013

Reprints and permission:

sagepub.co.uk/journalsPermissions.nav DOI: I0.1 I77// 3540688I35095I5 ppq.sagepub.com

(S) SAGE

\author{
Gregor Zons \\ University of Cologne, Cologne, Germany
}

\begin{abstract}
Quantitative studies aiming at general explanations for the emergence of new political parties stress the importance of new issues and the programmatic behaviour of other parties. I connect these two aspects by arguing that the programmatic diversity of existing parties is a strong influence on the incentives for new party formation, as it determines the scope for possible programmatic innovations. I use two measures for programmatic diversity in order to capture the programmatic supply by existing parties. It can be shown that the explanatory contribution of programmatic factors is as high as or even higher than that of the factors usually cited in the literature on new political parties, e.g. electoral institutions. Moreover, the results underline the necessity of differentiating between genuinely new parties and splits from existing parties as subtypes of new political parties.
\end{abstract}

\title{
Keywords
}

Conceptual definition, measurement, new parties, statistical analysis

\section{Introduction}

Over recent decades, developed democracies have seen a considerable number of new political parties, including green and right-wing parties. The literature on new political parties offers explanations for cross-country variation in the emergence of new parties, relying on electoral institutions (Willey, 1998) and sociological factors (cleavages) which are in general persistent over time. In addition, there are qualitative studies emphasizing the influence of new programmatic offerings in the context of the formation of new parties (Ignazi, 1992; Müller-Rommel, 1993). Similarly, quantitative studies aiming at general explanations for the phenomenon of new party formation mention the importance of new issues (Hug 2001; Tavits 2006). This study aims at contributing to this line of research by investigating the influence of the programmatic supply by existing parties on the formation of new political parties over time in a cross-country design.

This analysis adds to approaches which tie in with models of strategic entry (Cox, 1997; Tavits, 2006). The basic idea of these models is that the formation of a new political party is the result of a calculation by rational actors who balance the costs of formation on the one hand against, on the other hand, the benefits of office as well as the probability of being elected. As the following analysis includes the programmatic supply of the existing parties, which determines the possible leeway for programmatic innovations by new competitors, it takes account of the fact that the decision to form a new party is dependent on the behaviour of other actors in the arena. I argue that the programmatic level of party competition is central to the incentives to form a new political party. To capture the programmatic supply, I use two measures for programmatic diversity of political parties. The quantitative approach also enables a comparison of the explanatory power of the introduced programmatic factors and factors usually cited in the literature. In addition, whereas previous quantitative studies treated both genuinely new parties and splits from existing parties as new parties, without checking for any differences in their formation process, the following empirical analysis differentiates between both subtypes.

A better understanding of the formation of new parties is also essential for the understanding of their success (Hug, 2000), as these phenomena are interlinked but not identical with regard to their explanatory factors (Harmel and

Paper submitted 29 December 2012; accepted for publication 4 August 2013

\section{Corresponding author:}

Gregor Zons, Department of Political Science, University of Cologne, P.O. Box 4I 10 20, 50870 Cologne, Germany.

Email: gregor.zons@uni-koeln.de 
Robertson, 1985: 502). Although many newly formed parties never achieve electoral success, the few successful ones represent a subsample of this larger group. Assuming that their success is at least partly attributable to the prospect of programmatic innovations, it is necessary to examine how the leeway for such innovations affects the formation of new parties in the first place. Even without making electoral inroads, newly formed parties are relevant, as existing parties may react to their emergence and their policy offerings (Meguid, 2005, 2008). The focus on the programmatic level of party competition also speaks to the literature on the stability of party systems and the functioning of party competition in general. As this study demonstrates that the emergence of new political parties is linked to the programmatic level of party competition, it indicates that this is an expression of programmatic innovation, which is an important condition for functioning competition between parties (Franzmann, 2011: 330).

\section{Theory on the formation of new parties}

One of the most prominent arguments in the literature on new political parties is 'that new parties are formed primarily to fill representational needs' (Harmel and Robertson, 1985: 502) and respond to dissatisfied voters (Hauss and Rayside, 1978: 38). Apart from the demand side, this quote hints at the importance of the behaviour of political parties on the programmatic level of party competition. Studies of single parties and party families have addressed this point by looking at the programmatic offerings of existing parties with respect to certain issues (Müller-Rommel, 1993). Quantitative studies aiming at a general explanation for the emergence of new political parties mention the concept of new issues, which also touches on the relationship between the programmatic supply and electoral demands. In this article, I concentrate on the programmatic supply side of the political market. I argue that diversity of the programmatic supply by existing parties determines the leeway for programmatic innovations by new challengers and represents an important factor in the process of new party formation. The consideration of factors linked to the behaviour of parties on the programmatic level of party competition is important as it can account for variation in the number of new parties over time.

Theoretical models in quantitative studies on the phenomenon of new party formation have addressed the importance of the programmatic supply side to various degrees. Hug (2001), in his well-known work on new parties, develops a game-theoretic model to explain their formation. The actors in this game are an existing party and a potential new party. The result of this model depends on the response of the existing party to demands by potential challengers under the condition of uncertainty. Thereby, the formation of a new party follows from the programmatic behaviour of existing parties. On the basis of this model, Hug (2001: 54 ff.) states five hypotheses which influence the probability of new party formation. Among them is that the probability of new parties emerging increases with the importance of new issues.

Tavits (2006) starts with a general rational choice model which comes from Cox's (1997) illustration of entry models and describes the rational calculus of elites deciding whether to form a new party or not. According to this calculus, a formation occurs when the valuation of the benefits of holding political office and the (expected) probability of getting elected exceeds the costs of forming a new party. As this calculus is very general, it is important which factors are connected to these three parameters.

The probability of getting elected has to be assessed by the potential new party before the election and before its decision to participate in it. Actors are assumed to look at previous elections to estimate their potential electoral success. Beyond this assumption, there is the argument that the strength of voters' commitments to particular parties is increasing in the age of a democracy as the viability of parties grows more and more apparent (Tavits, 2008: $116 \mathrm{f}$.). Taking a line similar to Hug, Tavits also states that 'if societal conditions are such that the probability of new issues emerging is high, then new parties should be more frequent' (Tavits, 2006: 103). The concept of new issues also points to the importance of the programmatic level of party competition as it affects the conditions for connecting to electoral demands in the first place.

In order to capture the importance of the programmatic supply side, I tie in with theories about party competition which differentiate between the sides of the parties and the voters. Robertson (1976, 2006), in contrast to Downs (1957), who assumes that parties and voters are part of the same political space, starts from two political spaces: one of parties and one of voters. Building on this distinction, one can see that the two spaces differ in their dimensionality and their dominant issues, and therefore do not have to be congruent. Following this line of thought, Franzmann (2011: 330 ) uses the concept of the issue market, in which issues are the goods traded between parties (supply side) and voters (demand side). In an equilibrium on the issue market the programmatic supply of the political parties would perfectly cover all voters' demands, or, in other words, there would be a perfect congruence between parties' programmatic offerings and voters' demands. However, the existence of such an equilibrium over time is highly unlikely. Owing to imperfect information, party actors are not entirely certain about voters' (future) demands or their electoral consequences (Hug, 2001: 50 f.), the more so because of a constantly changing environment. Added to this, parties might not be able or willing to adapt their programmatic profiles, for example due to intra-party reasons (Robertson, 1976: 38). These factors lead to the contestability of the issue market and the vulnerability of incumbent parties. They give incentives and opportunities for political entrepreneurs to offer new programmatic ideas to the electorate. I call these 
'programmatic innovations', as 'innovation' refers to the actual introduction of a given policy idea (Hindmoor, 2008: 499).

I differentiate two types of programmatic innovation. The first is the promotion of new issues not yet addressed by the existing parties. This includes issues that were covered by parties in the past but subsequently lapsed, as the handling of an issue may vary over time due to an everchanging environment. The second type of innovation refers to the way parties think about politics in general and how they structure their programmatic offerings. According to Robertson (2006: 172), political parties are not completely flexible in the political party space. They hold certain 'governing methodologies', 'an idea, a methodology, a prime value, which tends towards organising a party's policy offerings across all of what it does'. Here, there exists another possible source of innovation. A political entrepreneur can come up with a new mode of policymaking in general which could enable a new combination of already existing but unconnected issues or a combination of old and new issues. Programmatic innovations can connect to unsatisfied demands and in this way respond to representational needs. Lago and Martinez (2010) call these situations electoral market failures. However, political entrepreneurs may also conceive innovations for which they first have to stimulate demand (de Vries and Hobolt, 2012). This means that preference shaping between parties and the electorate occurs in both directions but, irrespective of the direction of preference shaping, the introduction of a new programmatic offering which I call programmatic innovation is the precondition to trigger and connect to electoral demands. Additionally, although programmatic innovations are not guaranteed to meet the approval of voters, they nevertheless offer the opportunity to appeal to them in the first place. The leeway for possible innovations is dependent on the range of policies offered by the existing parties. The less diverse the existing supply, the more leeway there is for innovations by new contestants. The diversity of the programmatic supply by existing parties follows from two factors. The first is the overall issue coverage of all parties and comprises all issues which are addressed at least by one party and, in this way, are part of the programmatic competition between parties. The second factor refers to the actual programmatic differences between parties. All in all, this leads to the first hypothesis:

Hypothesis 1: The probability of new party formation increases with a lower diversity of the programmatic supply by existing parties.

With regard to the benefits of office, Tavits (2006: 104) argues that the benefits of holding political office vary according to the opportunity for influencing policies. This general argument is then linked to the type of interest mediation: corporatist arrangements are expected to show fewer newly formed parties than pluralist systems, as the former provide channels for influencing policies apart from the parliamentary arena. The dispersal of power across state institutions should also be relevant to the decision process about party formation. A higher number of veto points in a political system increases the possibilities of influencing policies. Yet only party actors have access to these veto points. ${ }^{1}$ Consequently, the second hypothesis reads as:

Hypothesis 2: The probability of new party formation increases with the number of veto points that are accessible for party actors.

Turning to formation costs, the literature emphasizes that higher costs lower the probability of new party formation (Hug, 2001; Tavits, 2006). The costs are determined by the electoral system and regulations with regard to party registration. The following analysis controls for these factors.

\section{Operationalization}

Previous quantitative studies follow Hug's (2001: 14) definition of new parties, according to which a new political party is defined as 'a genuinely new organization that appoints, for the first time, candidates at a general election to the system's representative assembly'. According to this definition, fissions and genuinely new parties are counted as new parties, whereas electoral alliances and fusions are excluded. However, studies which follow this classification do not verify whether their theoretical expectations hold for both subtypes, genuinely new parties and splits from existing parties, in the same way. I have argued that the programmatic supply of existing parties determines the possible leeway for policy innovations and in this way influence the incentive structure for new party formation. Although it is not impossible for splitting parties to innovate as described above, their formation process is expected to be linked to their party of origin rather than to the programmatic behaviour of all existing parties. Hence, in order to detect differences in the formation process of genuinely new parties and splits, the following empirical analysis differentiates between both of these subtypes.

\section{Data and measures}

The dataset covers 232 national legislative elections of 21 OECD democracies between 1960 and 2002. Hence, the units of observation are national elections. With regard to the dependent variable, I distinguish between genuinely new parties and splits from existing parties. Table 1 summarizes how the number of these two types of new parties is distributed over elections in each country ${ }^{2}$ and Table 2 shows the overall distribution of both variables.

With regard to the independent variables, it is important to find indicators that capture the programmatic supply by 
Table I. Distribution of genuinely new parties across countries over time.

\begin{tabular}{|c|c|c|c|c|c|c|c|c|c|c|c|c|c|c|c|c|c|}
\hline \multirow[b]{2}{*}{ Election } & \multicolumn{17}{|c|}{ Number of genuinely new parties and splits } \\
\hline & I & 2 & 3 & 4 & 5 & 6 & 7 & 8 & 9 & 10 & II & 12 & 13 & 14 & 15 & 16 & 17 \\
\hline \multicolumn{18}{|l|}{ Country } \\
\hline Australia & 0 & I & 0 & 0 & 0 & I & 0 & 0 & I & I & 0 & 1 & & 0 & 0 & 0 & \\
\hline$|963-200|$ & 0 & 1 & 0 & 1 & I & 0 & I & 0 & 0 & 0 & I & 0 & & 0 & 0 & 0 & \\
\hline Austria & I & I & 0 & 0 & I & I & 2 & 0 & 0 & 0 & 0 & 0 & & & & & \\
\hline $1962-1999$ & 0 & 2 & 0 & 0 & 0 & 0 & 0 & 0 & 0 & I & 0 & 0 & & & & & \\
\hline Belgium & 0 & 4 & 0 & 1 & 2 & 3 & I & 0 & 2 & 0 & 1 & 0 & 0 & & & & \\
\hline$|96|-1999$ & 0 & 0 & 0 & 0 & 0 & 0 & 0 & 0 & 0 & 0 & 1 & 0 & 0 & & & & \\
\hline Canada & 0 & I & 0 & 1 & I & 2 & 2 & 4 & 3 & & I & I & & & & & \\
\hline $1963-2000$ & 0 & 0 & 0 & 0 & 0 & 0 & 0 & 0 & 2 & & 0 & 0 & & & & & \\
\hline Denmark & 0 & 0 & 0 & 0 & I & I & 0 & 1 & I & I & 1 & 3 & 0 & 0 & 0 & 0 & 0 \\
\hline$|960-200|$ & I & 0 & I & I & 0 & I & 0 & 0 & 0 & 0 & 0 & 0 & 0 & 0 & 0 & I & 0 \\
\hline Finland & 0 & 0 & 0 & 0 & I & 0 & 2 & I & 0 & 0 & 0 & & & & & & \\
\hline $1962-1999$ & I & 0 & 0 & 0 & 3 & 0 & 0 & I & 0 & 0 & 0 & & & & & & \\
\hline France & 0 & I & 0 & I & 5 & 0 & 0 & 0 & 0 & 0 & 0 & & & & & & \\
\hline 1992-2002 & I & I & 0 & 3 & 4 & 2 & 2 & 0 & 0 & 0 & 0 & & & & & & \\
\hline Germany & 2 & I & I & 2 & 2 & 4 & I & 3 & I & & & & & & & & \\
\hline $1961-1990$ & 0 & 0 & 0 & 0 & 0 & 0 & 2 & 0 & 0 & & & & & & & & \\
\hline Greece & 3 & 0 & 2 & 1 & 0 & 0 & 0 & 0 & 0 & & & & & & & & \\
\hline $1977-2000$ & 2 & 2 & 0 & 2 & 3 & 0 & I & 1 & 0 & & & & & & & & \\
\hline Iceland & I & 0 & I & 0 & I & I & 4 & 0 & 0 & & & & & & & & \\
\hline $197 \mid-1999$ & 0 & 0 & 0 & 0 & I & 3 & 0 & 1 & 2 & & & & & & & & \\
\hline Ireland & 0 & 0 & I & 0 & I & 2 & I & 2 & I & 0 & 0 & 1 & 0 & & & & \\
\hline $196 \mid-2002$ & I & 0 & 0 & 2 & 2 & I & I & 0 & I & 0 & 1 & 0 & 0 & & & & \\
\hline Italy & 0 & 0 & 0 & 4 & 2 & 2 & 5 & I & & 0 & 1 & & & & & & \\
\hline$|963-200|$ & 0 & 1 & 2 & 0 & 0 & I & 0 & 0 & & 1 & 0 & & & & & & \\
\hline Luxembourg & 0 & 0 & 3 & 1 & 2 & 0 & 0 & & & & & & & & & & \\
\hline $1968-1999$ & 0 & I & I & 0 & I & 0 & 0 & & & & & & & & & & \\
\hline Netherlands & 0 & 2 & I & 1 & 0 & I & 0 & 0 & 0 & 0 & 0 & 1 & & & & & \\
\hline 1963-2002 & 0 & 0 & 3 & 0 & I & I & 0 & 2 & I & 0 & 0 & 0 & & & & & \\
\hline New Zealand & 0 & 0 & I & 1 & 0 & 0 & I & I & 0 & 0 & & & 0 & I & & & \\
\hline $1963-2002$ & 0 & 0 & 0 & 2 & 0 & 0 & 0 & 0 & 0 & 0 & & & I & I & & & \\
\hline Norway & 0 & 0 & 0 & 3 & 0 & 0 & 0 & 2 & 0 & 0 & 0 & & & & & & \\
\hline $196 \mid-2002$ & I & 0 & 0 & 3 & 0 & 0 & 0 & 1 & 0 & 0 & 0 & & & & & & \\
\hline Portugal & 0 & 0 & 0 & I & 0 & 3 & 0 & I & 0 & & & & & & & & \\
\hline 1979-2002 & 4 & 2 & 0 & 0 & 0 & 0 & 0 & 0 & 0 & & & & & & & & \\
\hline Spain & 5 & 1 & 9 & 2 & 0 & 0 & 0 & & & & & & & & & & \\
\hline 1979-2000 & 0 & 3 & 2 & 8 & 0 & 0 & 0 & & & & & & & & & & \\
\hline Sweden & 0 & 1 & 0 & 0 & 0 & 0 & 0 & I & 0 & 0 & I & 0 & 0 & 0 & & & \\
\hline 1960-2002 & 0 & 0 & I & I & 0 & 0 & I & 0 & 0 & 0 & 0 & 0 & 0 & 0 & & & \\
\hline Switzerland & 2 & 0 & 2 & 1 & 2 & 2 & I & 0 & 0 & & & & & & & & \\
\hline 1967-1999 & 0 & 4 & 0 & 0 & 0 & 0 & 0 & 0 & 0 & & & & & & & & \\
\hline UK & I & 0 & 0 & 4 & 0 & 3 & 1 & 3 & 0 & 0 & 0 & & & & & & \\
\hline$|964-200|$ & 0 & 0 & 2 & 2 & 0 & 8 & 2 & I & 0 & 0 & 0 & & & & & & \\
\hline
\end{tabular}

The first row in each country cell refers to the number of genuinely new parties, the second to the number of splits.

political parties as closely as possible (Selb and Pituctin, 2010: 148). Parties' manifestos provide the opportunity to follow the programmatic offerings made to the voters. Because of the time span involved, I use the data of the Comparative Manifestos Project (CMP) (Budge, 2001; Klingemann, 2006). In this project, party manifestos were coded on the basis of a number of predefined categories. For example, a number of 4.6 for a given party $A$ at election at time-point $t$ with regard to category $z$ means that in terms of content 4.6 percent of the (quasi-)sentences in that party manifesto can be subsumed under this category.

In order to measure the diversity of the programmatic offerings made by existing parties, I rely on two different measures. The first is the number of categories in the CMP scheme which show zeros for all given parties at a given election, meaning that the related issues are not addressed by any of the existing parties. These issues are not part of the programmatic competition between parties. Hence, this 
Table 2. Overall distribution of the number of genuinely new parties and splits.

\begin{tabular}{lcc}
\hline Counts & Genuinely new parties & Splits \\
\hline 0 & 127 & 159 \\
1 & 63 & 42 \\
2 & 22 & 19 \\
3 & 10 & 7 \\
4 & 6 & 3 \\
5 & 3 & 0 \\
6 & 0 & 0 \\
7 & 0 & 0 \\
8 & 0 & 2 \\
9 & 1 & 0 \\
Total & 185 & 129 \\
Mean & 0.80 & 0.56 \\
Std. Dev. & 1.22 & 1.11 \\
N & 232 & 232 \\
\hline
\end{tabular}

number is a measure for the overall issue coverage by all existing parties. This approach assumes that not only do positive values in the CMP dataset reflect parties' behaviour but so do the zero values. ${ }^{3}$ This first measure mainly indicates the leeway for the first type of programmatic innovation (new or neglected issues).

The second measure, invented by Franzmann (2008), reflects the differences between parties in the number of categories which are actually addressed by at least one party. Thus, in contrast to the first measure, this second measure only focuses on issues which are part of the programmatic competition between parties. The programmatic heterogeneity for country $c$ at time-point $t$ reads as follows:

$$
\operatorname{Het}_{c t}=\frac{\frac{1}{K-z} \sum_{i=1}^{K-z} s_{i c t}^{2}}{\sqrt{P_{c t}}}
$$

In the formula, $K$ stands for the overall number of categories in the CMP dataset and $z$ for the number of categories which show zeros for all given parties. $s_{i c t}^{2}$ is the variance of the salience scores of the parties in category $i$ and $P_{c t}$ represents the number of parties. This means that the programmatic heterogeneity is measured as the averaged variance of the salience scores over $K-z$ categories, corrected by a factor for the number of parties. ${ }^{4}$ This measure indicates the leeway for the second type of innovation (new combinations of issues). In general, there is a high positive correlation $(\mathrm{r}=0.55)$ between both measures. In part, this is due to the fact that the number of categories not addressed is included in the formula for programmatic heterogeneity. However, the correlation, when the latter is not adjusted by the number of zero categories, still amounts to $r=0.40$. This means that a higher number of nonaddressed categories is associated with greater differences between parties in the remaining categories.

Both measures show variation between countries and over time. Table 3 shows that on average the number of
Table 3. Average of programmatic diversity measures over time.

\begin{tabular}{lccc}
\hline & $\mathrm{N}$ & $\begin{array}{c}\text { No. of zero } \\
\text { categories }\end{array}$ & $\begin{array}{c}\text { Programmatic } \\
\text { heterogeneity }\end{array}$ \\
\hline $1960-1969$ & 43 & 14.77 & 3.77 \\
$1970-1979$ & 61 & 13.28 & 3.52 \\
$1980-1989$ & 63 & 11.13 & 2.61 \\
$1990-2002$ & 65 & 9.43 & 2.35 \\
Overall & 232 & 11.89 & 2.99 \\
\hline
\end{tabular}

non-addressed categories decreases over decades. The same can be observed for the programmatic heterogeneity. On average, Sweden features the highest number of nonaddressed categories $(\varnothing=19)$ and the lowest number is found for Spain $(\varnothing=3)$. The highest programmatic heterogeneity on average exists in Finland $(\varnothing=6.78)$, the lowest in the Netherlands $(\varnothing=0.80)$. As the first hypothesis is linked to the homogeneity of the programmatic supply by existing parties, the scores for programmatic heterogeneity are multiplied by -1 . Thus, in the following, I use the term 'programmatic homogeneity' with regard to this measure. High values then indicate a high degree of homogeneity between the programmatic offerings by existing parties.

According to hypothesis 1 , the expectation is that the probability of party formation at election point $t$ increases with a lower diversity of the election at point $t-1$. I use the time lag because I assume that the decision process of forming a new party takes a certain amount of time, which is why the effect of the programmatic diversity at the time of a given election should first become visible at the time of the next election. The measures of programmatic diversity serve as indicators of the leeway for programmatic innovation. As argued above, such leeway is regarded as the main reference point for the expected long-term probability of getting elected.

The age of the democracy is included as a control variable. Assuming that voters' commitments to parties become more stable over time, the effect of the age of the democracy should be decreasing over time rather than being linear. Thus, its natural $\log$ is used in the analysis.

As previous studies do, I use three different variables as indicators of the costs of party formation: first, the size of the deposit necessary for a party registration; second, the number of signatures per million eligible voters which are required for access to the ballot; third, a dummy variable indicating whether parties receive state financial support. ${ }^{5}$ Apart from these factors, the electoral rules determine the difficulty of winning seats in parliament. In this context, Selb and Pituctin (2010: 148) criticize that 'effects of electoral institutions that primarily operate at the level of electoral districts are usually specified at the national level, albeit often with measures originally tailored for the constituency level'. Owing to the fact that other concepts (first and foremost programmatic diversity) are located at the national level, a shift of the analytical level from the 
Table 4. Descriptive statistics of the independent variables.

\begin{tabular}{|c|c|c|c|c|c|}
\hline Variable & $\mathrm{N}$ & Mean & Std. Dev. & Min & Max \\
\hline Registration costs & 232 & 0.0321983 & 0.1067622 & 0 & 0.77 \\
\hline Petition signatures (logged) & 232 & I.567942 & 2.066957 & $-0.693 \mid 472$ & 7.387919 \\
\hline Party financing & 232 & 0.5560345 & 0.4979245 & 0 & I \\
\hline Mean district magnitude & 232 & 16.93789 & 34.17475 & 1 & 150 \\
\hline Nat. threshold & 232 & 2.141145 & 0.9704201 & 0.4966888 & 4.651302 \\
\hline Age of democracy (logged) & 232 & 2.301835 & $0.45 \mid 4625$ & 0.6931472 & 3.135494 \\
\hline Integration & 232 & 3.255927 & I.09494| & 1.625 & 4.75 \\
\hline Inst. constraints & 232 & 1.88069 & I.374393 & 0 & 5 \\
\hline GDP & 232 & 2.560129 & $2.4 \mid 4856$ & -6.8 & 12.2 \\
\hline Unemployment & 232 & 5.359483 & 4.277627 & 0.1 & 22.4 \\
\hline Population (logged) & 232 & 9.10047 & 1.325679 & 5.32301 & 11.0359 \\
\hline Ethnic fragmentation & 232 & 0.7842672 & 0.2061256 & 0.23 & 0.96 \\
\hline Programmatic homogeneity & 232 & -2.987655 & 2.512055 & $-16.985 \mid 4$ & $-0.378407 \mid$ \\
\hline No. of 'zero' categories & 232 & II.89224 & 6.125069 & 0 & 33 \\
\hline
\end{tabular}

national to the district level is not feasible in this study. Instead, two measures which are located at the national level depict the influence of the electoral system. First, the mean district magnitude captures the disproportionality of the transformation of votes into seats. ${ }^{6}$ Second, the national threshold of representation (Taagepera, 2002) measures the difficulty for a party to win its first seat in parliament. ${ }^{7}$

The model employs two indicators of the benefits of holding office. In order to take into account Tavits's (2006: 111 f.) significant findings concerning corporatism, I use Siaroff's (1999) integration index. I additionally include an index of institutional constraints on central state government ${ }^{8}$ as a measure related to veto points in order to capture the spread of power over policies in state institutions.

The dataset includes two variables which can be linked to society: the size of the population (logged) and ethnic fragmentation. ${ }^{9}$ Additional variables control for the influence of economic factors on voting behaviour. These are the GPD per capita growth and the unemployment rate. ${ }^{10}$ Table 4 gives the descriptive statistics for all independent variables.

\section{Analysis}

The two count variables for the number of genuinely new parties and splits per election differ in their distribution (Table 2). In particular, in the case of splits, the count variable shows a higher number of zero counts. In order to enable a comparison between both phenomena, in a first step these count variables are transformed into binary variables indicating the occurrence of either subtype. This transformation allows the use of a logistic regression in both cases. Pooled time-series cross-section data are prone to heteroskedasticity and serial correlation causing observations to be dependent on each other. In order to account for country clustering robust standard errors are used. With regard to the temporal dependence, two variables are included in a preliminary analysis (Beck et al., 1998). The first counts the number of elections since the previous occurrence (of a genuinely new party in the first model or a split in the second model). The second captures the number of previous occurrences. Only the second variable appears to be significant (at the 1 percent level) in the case of splits and is included in model presented below.

The results of the logistic regression (Table 5) for both subtypes, genuinely new parties (model M1) and splits (model M2), reflect similarities but also important differences with regard to the explanatory factors. The high Wald statistics show the overall significance of both models.

With regard to the variables linked to the probability of electoral support, the results show that the lagged programmatic homogeneity does not have any significant effect on the occurrence of either subtype. However, the number of categories that are not raised by any party has a positive effect on the probability of the occurrence of genuinely new parties. This effect is significant at the 5 percent level. The coefficient amounts to 0.076 , meaning that the nonaddressing of an additional category leads to a 0.076 increase in the log-odds of the dependent variable linked to the occurrence of genuinely new parties. A higher number of non-addressed categories indicates a less overall issue coverage by the existing parties. Hence, this finding supports the first hypothesis, as the probability of the occurrence of genuinely new parties is expected to increase with a lower overall issue coverage by the existing parties. In contrast, this variable shows no significant effect on the probability of the occurrence of splits. This result underlines the proposition that factors reflecting the diversity of programmatic offerings by all existing parties influence the incentive structure for the formation decision in the case of genuinely new parties, but not splits.

Differences between the subtypes also become apparent in respect of the indicators linked to the benefits of 
Table 5. Regression results.

\begin{tabular}{|c|c|c|c|c|}
\hline & MI & $M 2$ & \multicolumn{2}{|c|}{ M3 } \\
\hline & Genuinely new parties & Splits & \multicolumn{2}{|c|}{ Genuinely new parties } \\
\hline & Occurrence & Occurrence & \multicolumn{2}{|c|}{ Number } \\
\hline & (log. regression) & (log. regression) & \multicolumn{2}{|c|}{ (neg. bin. regr.) } \\
\hline & b / (se) & b / (se) & b / (se) & std. $\% \Delta$ \\
\hline Registration costs & $-2.007^{* *}(0.590)$ & $-0.000(1.594)$ & $-1.574 *(0.634)$ & -15.5 \\
\hline Petition signatures (logged) & $0.089(0.056)$ & $0.054(0.174)$ & $0.168 * *(0.038)$ & $4 I .4$ \\
\hline Party financing & $-0.093(0.247)$ & $-1.316(0.845)$ & $-0.162(0.243)$ & \\
\hline Mean district magnitude & $0.007^{*}(0.003)$ & $0.017^{* *}(0.004)$ & $0.003(0.002)$ & \\
\hline Nat. threshold & $-0.157(0.156)$ & $-0.057(0.220)$ & $-0.129(0.089)$ & \\
\hline Age of democracy (logged) & $-0.326(0.376)$ & I.I86 (0.707) & $-0.432 *(0.200)$ & -17.7 \\
\hline Integration & $-0.260 *(0.102)$ & $-0.179(0.308)$ & $-0.24 I * *(0.085)$ & -23.2 \\
\hline Inst. constraints & $0.270 *(0.123)$ & $-0.529 *(0.209)$ & $0.129 *(0.063)$ & 19.3 \\
\hline No. of previous splits & & $-0.768 * *(0.176)$ & & \\
\hline GDP & $0.029(0.053)$ & $-0.010(0.055)$ & $-0.016(0.028)$ & \\
\hline Unemployment & $-0.019(0.038)$ & $0.144^{* *}(0.053)$ & $0.004(0.025)$ & \\
\hline Population (logged) & $0.030(0.134)$ & $0.222(0.316)$ & $0.127(0.092)$ & \\
\hline Ethnic fragmentation & $-1.453^{* *}(0.545)$ & $6.968 * *(1.353)$ & $-0.578(0.342)$ & \\
\hline Prog. homogeneity (lagged) & $0.075(0.059)$ & $-0.020(0.053)$ & $0.072 *(0.032)$ & 24.1 \\
\hline No. of 'zero' categories (lagged) & $0.076 *(0.031)$ & $-0.069(0.042)$ & $0.039 *(0.018)$ & 28.2 \\
\hline Constant & $1.247(1.975)$ & $-7.257(4.204)$ & $0.307(1.217)^{\prime}$ & \\
\hline Wald & 320.45 & 171.91 & 794.94 & \\
\hline Alpha & & & $0.505(0.237)$ & \\
\hline$N$ & 232 & 232 & 232 & \\
\hline
\end{tabular}

$*_{p} \leq 0.05, *_{p} \leq 0.01$. Country clustered standard errors.

office. Integration, the indicator for corporatism, displays a negative effect (significant at the 5 percent level) on the dependent variable for the first model (M1), while no effect is visible in the case of splits (model M2). The negative effect for genuinely new parties is in line with the theoretical expectation that corporatist arrangements feature less new political parties than pluralist systems, as the former provide channels for influencing policies apart from the parliamentary arena. As actors deciding about a split from an existing party are likely to be already part of this arena, channels apart from the electoral arena should be of less importance. Institutional constraints on central state government have different effects on each subtype. Their significance ( 5 percent level) underlines the fact that the distribution of power in a political system influences the incentive structure for new party formation. For genuinely new parties the effect of institutional constraints on central state government is positive. Tighter constraints on central state government mean that there are more veto points outside the government, increasing the potential to influence policies. Assuming that actors deciding whether to form a completely new party have an out-of-government perspective, they benefit from such constraints. In the case of splits, institutional constraints show a negative effect. This indicates that for parties originating from splits the government perspective is more relevant than it is for genuinely new parties or that they fear losing access to veto points occupied by the party of origin.

Considering the variables linked to the formation costs, the registration costs show a significant (at the 1 percent level) and negative effect for the first model, M1. This means that the probability of the occurrence of genuinely new parties decreases as registration costs rise. The direction of this effect fits the expectation that higher costs should reduce the probability of new parties. However, this effect is not present in the model for splits, M2, indicating that financial obstacles do not prevent the occurrence of splits. This could be explained by different levels of financial resources of genuinely new parties and splits. The logged number of necessary signatures, as well as the dummy variable indicating party funding by the state, do not show any significant effects for either subtype. This does not necessarily mean that state financing does not influence the incentives for forming a new party. However, the existence of state financing could also work against new parties if the rules favour established ones. For example, funding could be related to the achievement of a certain threshold of votes. The mean district magnitude has a positive effect on the occurrence of both subtypes, significant at the 5 percent (M1) and 1 percent level (M2). This effect is hence in line with the theoretical expectation: a higher 
mean district magnitude implies lower formation costs as it is easier to win seats in parliament. As opposed to this effect, the national threshold of representation has no significant effect in both models. This result suggests that the overall disproportionality between votes and seats matters more than the chance of winning the first seat in parliament (Bischoff, 2008). The results of models M1 and M2 reveal no significant effects of the age of democracy on either subtype.

There are also mixed results from the societal variables. No significant effects on either subtype can be found for the (logged) population size. However, ethnic fragmentation shows significant (1 percent level) but opposing effects. In the case of splits, the effect has a positive sign. As higher values indicate lower levels of ethnic fragmentation, the probability of the occurrence of splits therefore decreases as ethnic fragmentation grows. Genuinely new parties experience the opposite effect. The probability of the occurrence of genuinely new parties increases with level of ethnic fragmentation. This means that a higher level of ethnic fragmentation diminishes the opportunities for splits in existing parties, while at the same time improving prospects for genuinely new parties. Although this aspect needs further consideration, it may explain why previous studies which did not separate the subtypes found no significant effects for this variable as the results cancel each other out. With regard to the economic variables, the growth of GDP per capita displays no effect on the occurrence of genuinely new parties or splits. The unemployment rate shows a significant and negative effect in model M2, indicating that the probability of the occurrence of splits increases when unemployment rises. The negative effect of the number of previous splits in model M2 suggests that the probability of the occurrence of splits decreases with the number of previous splits. In sum, the results of the logistic regressions show that there are important differences in the ways the explanatory factors operate on the two subtypes. This underlines the necessity of differentiating between genuinely new parties and splits when analysing new political parties.

As the focus of this article is on programmatic factors, in the last part of the empirical analysis I concentrate on genuinely new parties. So far, I have focused only on their occurrence. The distribution of the counts of genuinely new parties, however, also provides the opportunity to make use of the whole variance of the number of genuinely new parties per election. The dependent variable is then the number of genuinely new parties for each election. Because of the distributional parameters, a negative binomial distribution is assumed. The results of the third model M3 are based on a generalized estimating equation (GEE) model, which in this case is based on a negative binomial distribution and belongs to the family of population-averaged panel-data models. In contrast to a simple negative binomial regression, this approach allows the temporal dependence of the observations (Hilbe, 2011: 450 ff.). ${ }^{11}$
The high Wald statistic shows the overall significance of the model and the estimate of alpha justifies the assumption of the negative binomial distribution. Similar to the first model, the number of zero categories has a positive effect on the expected number of genuinely new parties (dependent variable), which is significant at the 5 percent level. In the third model, the lagged programmatic homogeneity also shows a positive effect (significant at the 5 percent level) on the dependent variable. An increase in the lagged programmatic homogeneity leads to a higher expected number of genuinely new parties. The significance of both effects suggests that not only the overall issue coverage of all existing parties influences the incentive structure for the formation of genuinely new parties, but also the differences between the parties in the issues which are actually part of the programmatic competition between parties. Both of these effects support the first hypothesis. Contrary to the first model, the (logged) age of the democracy shows a negative effect (significant at the 5 percent level) in the third model, indicating that the probability of the occurrence of genuinely new parties is not influenced by the age of the democracy but that the latter diminishes the expected count of genuinely new parties.

In line with the first model, the results from the indicators linked to the benefits of office reveal that institutional constraints on central state government have a positive effect on the expected counts of genuinely new parties, which is significant at the 5 percent level. In the third model, the indictor of corporatism, integration, also has a negative effect (significant at the 1 percent level), which means that a higher level of corporatism decreases the expected counts of genuinely new parties. This resembles Tavits's findings (2006: 111) for new parties in general. Taking both of these effects together, this means that it is necessary to differentiate between different kinds of institutions. Corporatist arrangements offer opportunities for influencing policies from outside the parliamentary arena. State institutions constraining central government provide access to veto points which enable the exercise of influence over policies. However, this access is only gained through party channels.

The comparison with the logistic model for the occurrence of genuinely new parties shows that registration costs also have a negative effect (significant at the 5 percent level) in this model. Higher registration costs reduce the expected counts of genuinely new parties, supporting again the expectation about the formation costs. In contrast to the first model, the (logged) number of necessary signatures has a positive effect in this model, significant at the 1 percent level. Contradicting the theoretical expectation, an increase in the necessary number of signatures leads to a higher expected number of genuinely new parties. This effect is also found by Tavits (2006: 110 f.) with regard to all new parties. A possible explanation is that these requirements serve as an information shortcut about 
possible electoral support (Tavits, 2006: 111). Again, no effect is found for the public financing of political parties. Unlike in the first model, the mean district magnitude has no significant effect on the expected number of genuinely new parties. This means that this variable explains the occurrence of this subtype better than the actual number of new parties per election. In the third model, neither the societal nor the economic control variables show any significant effects on the expected counts of genuinely new parties.

So far, only the direction and significance of the effects have been considered. To examine the magnitude of the different effects, the variables showing significant effects in the third model are standardized. The last column of Table 5 shows the percentage changes in the expected number of genuinely new parties when one of the independent variables increases by one standard deviation. These numbers show that the (logged) number of necessary signatures has the strongest effect on the dependent variable. An increase of the first by one standard deviation leads to an increase in the expected number of genuinely new parties by 41.4 percent. Apart from that, the programmatic factors also show a high magnitude. The expected number of genuinely new parties rises by 28.2 percent when the (lagged) number of zero categories goes up by one standard deviation. For the (lagged) programmatic homogeneity this effect amounts to 24.1 percent. Comparison with the other significant effects suggests that these programmatic factors are not just statistically significant but also significant in terms of their magnitude.

\section{Conclusion}

In this study, I first argued that the diversity of the programmatic supply by existing parties represents an important factor in the process of the new party formation, as it determines the leeway for possible programmatic innovations. In order to capture this leeway, I introduced a measure for the overall issue coverage of political parties and a second measure for the programmatic differences between parties. Secondly, I pointed out that state institutions in the form of veto points are also relevant for the process of new party formation as they influence the benefits of office for new (potential) political parties.

Above all, the first part of the empirical analysis of the study showed the necessity of differentiating between genuinely new parties and splits from existing parties. Differences between the two subtypes were found in respect of factors linked to the diversity of the programmatic supply by existing parties. The overall issue coverage has a significant effect, but only on the occurrence of genuinely new parties: a lower issue coverage by the existing parties increases the probability of their occurrence. However, programmatic differences between parties are not able to account for the occurrence of either subtype. Another difference between the subtypes is revealed by the indicators relating to the benefits of office. Institutional constraints on central state government increase the probability of the occurrence of genuinely new parties but have the opposite effect in the case of splits. The first part of the empirical analysis also demonstrates that factors connected with the formation costs have a different impact on the occurrence of both genuinely new parties and splits. Registration costs hamper the occurrence of genuinely new parties but not the occurrence of splits, while the mean district magnitude has a positive impact for both subtypes. Moreover, the different effect of ethnic fragmentation on both subtypes underlines the need for differentiation between them, although this effect needs further investigation. These varying results represent a starting point for future research, investigating the causal mechanisms behind these differences.

The results of the second part of the empirical analysis, which focused on the number of genuinely new parties, confirm and strengthen the importance of programmatic factors for the incentive structure for their formation. Fewer differences between parties as well as lower overall issue coverage are associated with a higher expected number of genuinely new parties. The independent effects of factors linked to the programmatic supply raise the question of what role electoral demands play in the emergence of programmatic innovations and the formation of genuinely new parties in general. On the one hand, it is possible that programmatic innovations pick up so far unsatisfied electoral demands but, on the other hand, political actors can come up with innovations and try to stimulate electoral demand for them in the future. To detect such interactions, future research using quantitative methods should include finer measures of electoral demands.

Although the effects of the programmatic factors indicate the importance of the scope for programmatic innovations in the formation of genuinely new parties, this analysis, due to the lack of available data, could not examine the actual programmatic offerings of genuinely new parties. However, it offers a basis for additional research for a more detailed examination of programmatic innovations, for example by investigating their origins and how they are connected to electoral demands and influence them. This could also illuminate why and when actors choose certain types of programmatic innovations. These aspects are relevant with regard to the electoral success of genuinely new parties and their programmatic offerings.

\section{Acknowledgements}

I thank Simon Hug and Margit Tavits for generously providing their data.

\section{Funding}

The author(s) received no financial support for the research, authorship, and/or publication of this article. 


\section{Notes}

1. Franzmann (2011: $333 \mathrm{ff}$.) points out how different types of veto points affect the diversity of the programmatic supply. However, there does not exist an unequivocal relationship between the number of veto points in a political system and the diversity of the programmatic supply by political parties.

2. For elections until 1990, I rely on Hug's (2001) data retracing his original coding of both subtypes for his list of new parties. For the following elections, I followed Tavits's sources and counted the parties myself. A complete list of all parties counted is available on request. No reliable data on the number of new parties exist for the elections in 1993 in Australia, for the election in 1993 in Canada and for the elections in 1993 and 1996 in New Zealand. The election in 1994 in Italy is not included owing to the significant transformation of the electoral system and party system before this election (Bartolini and D'Alimonte, 1996). In the German case, only elections for West Germany until 1990 are included.

3. It has to be noted that the CMP coding scheme is the same for all countries. It is possible that there exist issues which are not captured by this coding scheme. (Quasi-)Sentences of manifestos that address such issues are subsumed into a single category for uncoded sentences which in general does not reach high values. Nevertheless, a category in the CMP coding scheme, which is not addressed by any party, shows at least that there is potential scope for innovation.

4. Quantitative measures with respect to parties often use voteshares as weights (see, e.g., Dalton, 2008). As the measures for programmatic diversity in this article should solely capture the programmatic diversity of political parties, I deliberately do not introduce vote-shares as weights to these measures as this would reverse the conceptual separation between the side of parties and the electorate and in this way undermine the conceptual validity of the measures.

5. As there exists no time-series that covers the whole period for these variables, I rely on the data of Hug (2001: $178 \mathrm{ff}$.) and Tavits (2006). Hug mainly took his numbers from the Interparliamentary Union (1976) as well as from Sternberger et al. (1969). Tavits used information from the International Institute for Democracy and Electoral Assistance. Deposits are measured in the local currency. Hug weighted these numbers by dividing them by GNP per capita. The values of this variable are present in his dataset, but could not be checked on the basis of the sources he cites. For observations after 1990 only the weighted values exist. With regard to GNP per capita, Tavits (2006: 166) refers to the Global Development Network Growth Database. However, this only features values for GDP; still, considering the relation between deposits and GDP/GNP per capita, the bias thus caused is marginal. The number of signatures necessary for registration is weighted by the number of registered voters. For the latter, data are available at http://www.idea.int/vt/index.cfm (29.10.12). Furthermore, a dummy variable indicates the presence of party funding by the state. For this, Hug relied on Paltiel (1981) and Tavits consulted http://www.idea.net. On the basis of IDEA (http://www.idea.int/political-finance, Question 19, 29.10.12), I corrected values for Belgium for the years after 1989 and for France after 1988.

6. For the mean district magnitude, I rely on the dataset 'Democratic Electoral Systems (DES)' (Bormann and Golder, 2013; Golder, 2005). In the case of Germany, I calculated the mean district magnitude on the basis of the second vote. Similarly, for elections after 1993 in New Zealand the mean district magnitude refers to the list vote.

7. The calculation is based on data of the DES dataset (Bormann and Golder, 2013; Golder, 2005). In multi-tier systems the threshold refers to the first tier, as this determines the access to seat allocations in the upper tiers. In case there is a threshold for participation in the allocation of seats in an upper tier which is lower than the national threshold of representation for the first tier, the latter is replaced by the former. This is the case for Denmark. If there is a legal threshold for the first tier which exceeds the national threshold of representation, the legal threshold is used (e.g. in Spain). For Germany, the calculation refers to the first vote.

8. The data come from the Comparative Political Data Set I (Armingeon et al., 2012) and are based on the work of Schmidt (1996). The index ranges from 0 to 6 . High values are a sign of strong constraints. The additive index is composed of six dummy variables: EU membership, degree of centralization of state structure, difficulty of amending constitutions, strong bicameralism, central bank autonomy and frequent referendums.

9. The data rest on a Herfindahl-Hirschman index of concentration for ethnicity (Tavits, 2006: 117). Data on ethnicity come from the CIA World Factbook (https://www.cia.gov/library/ publications/the-world-factbook/index.html, 29.10.12). The World Bank (http://data.worldbank.org/indicator/SP.POP. TOTL, 29.10.12) provides data on population size.

10. The data on the economic control variables come from the OECD Historical Statistics $(1982,1991,2002)$ and for elections after 2000 from the OECD (http://stats.oecd.org/index. aspx?queryid=559\# (20.06.13); DOI: 10.1787/lfs-data-en).

11. An autoregressive correlation structure is assumed (Hilbe, 2011: 462 ff.).

\section{References}

Armingeon K, Weisstanner D, Engler S, Potolidis P and Gerber M (2012) Comparative Political Data Set I 1960-2010. Bern: Institute of Political Science, University of Bern.

Bartolini S and D'Alimonte R (1996) Plurality competition and party realignment in Italy: The 1994 parliamentary elections. European Journal of Political Research 29: 105-142.

Beck N, Katz JN and Tucker R (1998) Taking time seriously: Time-series-cross-section analysis with a binary dependent variable. American Journal of Political Science 42: 1260-1288.

Bischoff CS (2008) National level electoral thresholds: Problems and solutions. Electoral Studies 28: 232-239. 
Bormann N-C and Golder M (2013) Democratic electoral systems around the world, 1946-2011. Electoral Studies 32: $360-369$.

Budge I (ed.) (2001) Mapping Policy Preferences: Estimates for Parties, Electors, and Governments, 1945-1998. Oxford and New York: Oxford University Press.

Cox GW (1997) Making Votes Count: Strategic Coordination in the World's Electoral Systems. Cambridge and New York: Cambridge University Press.

Dalton RJ (2008) The quantity and the quality of party systems party system polarization, its measurement, and its consequences. Comparative Political Studies 41: 899-920.

de Vries CE and Hobolt SB (2012) When dimensions collide: The electoral success of issue entrepreneurs. European Union Politics 13: 246-268.

Downs A (1957) An Economic Theory of Democracy. New York: Harper.

Franzmann ST (2008) Programmatische Heterogenität und ideologische Polarisierung in den europäischen Parteiensystemen [mimeo]. Cologne.

Franzmann ST (2011) Competition, contest, and cooperation: The analytic framework of the issue market. Journal of Theoretical Politics 23: 317-343.

Golder M (2005) Democratic electoral systems around the world, 1946-2000. Electoral Studies 24: 103-121.

Harmel R and Robertson JD (1985) Formation and success of new parties. International Political Science Review 6: 501-523.

Hauss C and Rayside D (1978) The development of new parties in Western democracies since 1945. In: Maisel LS and Cooper J (eds) Political Parties: Development and Decay, 31-57. Beverly Hills, CA: Sage.

Hilbe JM (2011) Negative Binomial Regression. Cambridge: Cambridge University Press.

Hindmoor A (2008) Policy innovation and the dynamics of party competition: A Schumpeterian account of British electoral politics, 1950-2005. British Journal of Politics \& International Relations 10: 492-508.

Hug S (2000) Studying the electoral success of new political parties - A methodological note. Party Politics 6: 187-197.

Hug S (2001) Altering Party Systems: Strategic Behavior and the Emergence of New Political Parties in Western Democracies. Ann Arbor, MI: University of Michigan Press.

Ignazi P (1992) The silent counter-revolution. Hypotheses on the emergence of extreme right-wing parties in Europe. European Journal of Political Research 22: 3-34.

Interparliamentary Union (1976) Parliaments of the World: A Reference Compendium. London: Macmillan.

Klingemann H-D (ed.) (2006) Mapping Policy Preferences II: Estimates for Parties, Electors, and Governments in Central and Eastern Europe, European Union and OECD 19902003. Oxford: Oxford University Press.

Lago I and Martinez F (2010) Why new parties? Party Politics 17: 3-20.
Meguid BM (2005) Competition between unequals: The role of mainstream party strategy in niche party success. American Political Science Review 99: 347-359.

Meguid BM (2008) Party Competition between Unequals: Strategies and Electoral Fortunes in Western Europe. Cambridge and New York: Cambridge University Press.

Müller-Rommel F (1993) Grüne Parteien in Westeuropa. Opladen: Westdeutscher Verlag.

OECD (1982) OECD Historical Statistics 1981. Paris: Organisation for Economic Co-operation and Development.

OECD (1991) OECD Historical Statistics 1990. Paris: Organisation for Economic Co-operation and Development.

OECD (2002) OECD Historical Statistics 2001. Paris: Organisation for Economic Co-operation and Development.

Paltiel KZ (1981) Campaign finance: Contrasting practices and reforms. In: Butler D, Penniman HR and Ranney A (eds) Democracy at the Polls: A Comparative Study of Competitive National Elections, 138-172. Washington, D.C.: American Enterprise Institute for Public Policy Research.

Robertson D (1976) A Theory of Party Competition. London and New York: J. Wiley.

Robertson D (2006) On the dimensionality of political space and on its inhabitants. In: Bara J and Weale AP (eds) Democratic Politics and Party Competition: Essays in Honour of Ian Budge, 159-178. London and New York: Routledge.

Schmidt MG (1996) When parties matter: A review of the possibilities and limits of partisan influence on public policy. European Journal of Political Research 30: 155-183.

Selb P and Pituctin S (2010) Methodological issues in the study of new parties' entry and electoral success. Party Politics 16: 147-170.

Siaroff A (1999) Corporatism in 24 industrial democracies: Meaning and measurement. European Journal of Political Research 36: 175-205.

Sternberger D, Vogel B and Nohlen D (1969) Die Wahl der Parlamente und anderer Staatsorgane. Ein Handbuch. Berlin: de Gruyter.

Taagepera R (2002) Nationwide threshold of representation. Electoral Studies 21: 383-401.

Tavits M (2006) Party system change. Testing a model of new party entry. Party Politics 12: 99-119.

Tavits M (2008) Party systems in the making: The emergence and success of new parties in new democracies. British Journal of Political Science 38: 113-133.

Willey J (1998) Institutional arrangements and the success of new parties in old democracies. Political Studies 46: 651-668.

\section{Author biography}

Gregor Zons is a doctoral student at the International Max Planck Research School on the Social and Political Constitution of the Economy (IMPRS-SPCE), University of Cologne, Cologne Center for Comparative Politics, P.O. Box 4110 20, 50870 Cologne, Germany. 